\title{
Borges, lector hedonista
}

\author{
Natalia BIANCOTTO \\ Universidad Nacional de Rosario (UNR)- Consejo Nacional de Investigaciones Científicas y \\ Tecnológicas (CONICET)
}

\section{RESUMEN}

En sus ensayos, reseñas y notas de los años treinta y cuarenta, Borges emprende una dura embestida contra el realismo y la psicología en la novela argentina. Entre las interpretaciones críticas de sus enunciados se ha generalizado la idea de que, por el valor que le atribuye al rigor constructivo, Borges vindica el género fantástico por oposición a la narración realista. Este trabajo propone revisar esta conclusión a partir de una lectura de los ensayos del autor correspondientes a este período, en función del solapado diálogo que éstos mantienen con ciertas ideas de Stevenson sobre el realismo y la novela. Los estudios que se ocuparon de la gravitación de Stevenson en la ensayística borgeana no han abordado aun lo que considero el nudo principal de los ensayos, esto es, la ética que los alienta. A partir de lo que defino como una ética del lector hedonista, intentaré argumentar que lo que funciona en ambos ensayistas es, antes que una verdadera impugnación del realismo, una contundente vindicación de la literatura de imaginación, que, al menos para Borges, no se identifica únicamente con la modalidad fantástica. Este diálogo permitirá poner en cuestión la manida imagen de un Borges antirrealista.

Palabras clave: Borges, Stevenson, realismo, ética de ensayista, lector hedonista.

\section{Borges, the hedonistic reader}

\begin{abstract}
In his essays, reviews and notes from the thirties and forties, Borges begins a harsh attack against the realism and psychologism of Argentinean novel. Among the critical interpretations of his statements it is widely believed that Borges vindicates the fantastic genre (for the value that he attributes to its constructive rigour) as opposed to realistic narrative. This work proposes to revise this conclusion from a reading of the author's essays of the period, based on the veiled dialogue they maintain with certain Stevenson's ideas about realism and novel. The studies that have dealt with the influence of Stevenson on Borgean essays have not reached yet what I consider is the main core of the essays, that is, their ethics. From what I define as an ethic of the hedonistic reader, I will attempt to argue that, rather than a true refutation of realism, both essayists make a strong vindication of imaginative literature, which, at least for Borges, refers not only to the fantastic genre. This dialogue will call into question the hackneyed image of an anti-realist Borges.
\end{abstract}

Key words: Borges, Stevenson, realism, essayist ethic, the hedonistic reader. 
La crítica borgeana ha disgregado en un prisma de personalidades las facetas de la producción del autor sobre las que le interesó focalizar: Borges crítico, Borges ensayista, Borges profesor, Borges narrador, Borges poeta, Borges político, Borges traductor ${ }^{1}, \ldots$ La profusión de "Borges más calificativo" nos invita a meternos en esa corriente de títulos con uno que quizás vaya a dar en el blanco de todos: un Borges que, ante todo, es un lector. Todo escritor -podría pensarse- es antes que escritor, un lector. Nos interesa volver aquí sobre las intervenciones polémicas de Borges en torno al realismo, a partir del lugar preponderante que, según nuestra lectura, manifiesta en ellas la figura del lector. El lector Borges, por un lado; el lector imaginado que sus ensayos invocan, por otro. Un contrapunto entre estos dos lectores (borgeanamente, acaso el otro es el mismo) permitirá iluminar viejas y nuevas respuestas a la pregunta sobre qué lee Borges cuando lee el realismo.

La línea de lecturas críticas que inaugura el ensayo de Enrique Pezzoni sobre Otras inquisiciones ${ }^{2}$ en 1952, y desarrollan los de Sylvia Molloy (1979) y Alberto Giordano (1991, 2005), entre otros, se ocupó de enfatizar el carácter estratégico y polémico de la ensayística borgeana. "[L]as poéticas que Borges propone en sus ensayos -dice Giordano- suelen ser, esencialmente, poéticas de combate”, cuyo interés es menos el de "establecer unívoca y taxativamente qué deben ser la literatura o un género, que impugnar criterios de valoración que, favorecidos por las ideologías culturales de la época, se impusieron como dominantes” (2005: 20). Como se sabe, durante las décadas del treinta y del cuarenta, Borges emprende una dura embestida contra el realismo y la psicología en la novela, con el doble propósito de desplazar el lugar preponderante que estas manifestaciones alcanzan en el campo cultural argentino e instalar allí su propia literatura y la de su grupo de escritores amigos, cuyas estéticas son afines. Éste es, de hecho, el impulso que anima sus reseñas a Adolfo Bioy Casares, José Bianco y Manuel Peyrou³ ${ }^{3}$ Pero la apuesta

${ }^{1}$ Me refiero a títulos como Borges crítico, de Sergio Pastormerlo (2007); Borges profesor, de Martín Arias y Martín Hadis (2000); “Borges, narrador”, de Amado Alonso (1935); “Jorge Luis Borges, poeta”, de Néstor Ibarra (1930); Borges y la traducción, de Sergio Waisman (2005); y a las figuras de un Borges político, al que se refiere Juan Pablo Dabove (2008), y la del Borges ensayista que construye Alberto Giordano en Modos del ensayo. Jorge Luis Borges - Oscar Masotta (1991), cuyo antecedente ya se encuentra en el libro de 1988, en colaboración con Sergio Cueto, Borges y Bioy Casares ensayistas.

${ }^{2}$ Con el título “Aproximación al último libro de Borges”, lo publica en Sur 217-218 (Pezzoni 1952), y lo incluye después en El texto y sus voces (1986).

${ }^{3}$ Dichas reseñas, de las que me ocuparé oportunamente, son: "Luis Greve, muerto", de 1937, dedicada a la novela de Adolfo Bioy Casares (Borges, 1999a: 149-50); "Las ratas”, de 1944, a la novela de José Bianco (Borges 1999a: 271-74); y “La espada dormida”, de 1945, a la de Manuel Peyrou (Borges, 1999a: 282-83). 
fuerte de esta operación es la que pone en marcha en los ensayos "La postulación de la realidad”, de 1931, y "El arte narrativo y la magia”, de 1932, para dar su estocada final en 1940, con el prólogo a La invención de Morel de Adolfo Bioy Casares. Allí Borges impacta contra la centralidad del humanismo literario de Sur, representado principalmente por las novelas de Eduardo Mallea, según precisó Judith Podlubne (2011). Valiéndose para sus propios fines de una versión simplificada de las tesis de José Ortega y Gasset en "Ideas sobre la novela"4, Borges aprovecha la dicotomía orteguiana entre novela de aventuras y novela de personajes para, por un lado, disparar contra esta última identificándola maliciosamente con la novela psicológica malleana, y por otro, tomar partido por la primera como emblema de una poética del relato riguroso, ordenado y austero (Podlubne, 2011: 69-81).

La estrategia de combate de Borges fue leída también como profesión de fe. María Teresa Gramuglio (1989) afirmó que Borges procede a una "verdadera vindicación del fantástico como un género que, por su rigor constructivo, puede oponerse a la narración realista por entonces predominante en la Argentina” (12). Esta conclusión se generalizó al punto de ocultar que la oposición realismo/fantástico en Borges es menos atribuible a una ética literaria del autor que a las interpretaciones críticas de sus enunciados. Desconociendo el estatuto provisional y estratégico de las afirmaciones borgeanas, las más inteligentes lecturas críticas suscriben a la dicotomía con la que Borges urde su maniobra. Según Daniel Balderston (1985), al "fantasma" de la novela realista, Borges y Bioy le "oponen 'la literatura fantástica', estrechamente vinculada con las ideas de Stevenson sobre la novela romántica y la novela de aventuras" (25). Isabel Stratta (2004) retoma estas ideas y, a partir de un análisis comparativo con los ensayos de Stevenson, concluye que "[f]rente al realismo -que él [Borges] percibe como el imperio de lo prosaico y al que opta arbitrariamente por negarle cualquier virtud artística- $\mathrm{y}$ frente a la unanimidad reverencial que las novelas suscitan en su medio" (53), Borges reacciona reivindicando el modo fantástico, la poética de lo extraordinario y “el espíritu del romance inglés” (ídem).

Stratta acierta en señalar que, en su embate contra el realismo y la psicología en la novela, Borges se apropia de ciertos argumentos que Stevenson había formulado cincuenta años antes en su polémica con la novela realista francesa (ídem). Un agudo análisis de la incidencia de Stevenson en el plan general de la obra de Borges es el que presentó el trabajo pionero y hoy ineludible de Daniel Balderston (1985). En este sentido, me propongo extender el diálogo entre los ensayos de Borges y los de Stevenson, con el objetivo de poner en cuestión la tan manida imagen de un Borges antirrealista. Si hasta el momento se estudió la gravitación de Stevenson en la ensayística borgeana de los años treinta y cuarenta fundamentalmente en torno a

\footnotetext{
${ }^{4}$ Ensayo publicado en 1925 junto con La deshumanización del arte.
} 
dos rasgos, como son, por un lado, las postulaciones contra el detalle en la narrati$\mathrm{va}^{5}$, y por otro, la defensa de una poética de lo extraordinario identificada con el romance, aún no se ha ponderado suficientemente lo que considero el nudo principal de los ensayos, esto es, la ética que los alienta.

"Stevenson" no sólo es la primera palabra que Borges pronuncia en el prólogo a La invención de Morel, sino el nombre que gravita sobre ciertos núcleos conceptuales fuertes que atraviesan el texto: "novela de aventuras", "peripecia”, "ejecución”, "clásico". Más allá de la cita inicial, en el prólogo "la argumentación y la terminología de Borges provienen de Stevenson” (Balderston, 1985: 24). A pesar de que la invectiva dirigida contra la "novela psicológica" que "quiere ser también novela realista" (Borges, 2005: 8) es presentada como una respuesta a la defensa que hace Ortega del género, parece evidente que Borges está leyendo menos las "Ideas sobre la novela” que los ensayos de Stevenson sobre el realismo. Se advierte, en este sentido, que en sus sucesivas intervenciones críticas de los años treinta y cuarenta, de las que el Prólogo sería una suerte de culminación ${ }^{6}$, Borges lee el realismo en la Argentina leyendo a Stevenson. Pero es sobre todo en la formulación de una ética de lector desde la que, al tiempo que desplaza la centralidad de la novela realista sostiene su propia idea de ficción, que el legado de Stevenson se revela eficaz.

${ }^{5}$ Balderston (1985) se refiere a las prescripciones técnicas según las que ambos recomiendan abolir el exceso de detalles en la narración:

\begin{abstract}
Al igual que el tratamiento que Stevenson da a las imágenes visuales, las técnicas de Borges son primordialmente reacciones contra modelos literarios considerados defectuosos, porque adormecen al lector llevándolo a la sumisión en vez de obtener su activa participación en el proceso imaginativo. En vez de describir lenta y cuidadosamente una escena, ambos escritores prefieren ponerla en movimiento prestando atención al contraste, iluminando detalles visuales brillantes (y fácilmente imaginables por el hecho de ser escasos) y gestos melodramáticos. (61)
\end{abstract}

Asimismo, Stratta (2004) afirma que "La postulación de la realidad” es el primer discurso de Borges "contra la representación realista y la ocasión para su heterodoxa definición de 'clasicismo', destilada libérrimamente, y sin mención de fuente, de un ensayo de Stevenson contra el detalle en la literatura” (52).

${ }^{6}$ Considerado por la crítica el texto “cuasiprogramático” por excelencia -dado que no existe un programa o declaración de principios manifiestamente formulado- de la poética borgeana del relato, condensaría las “cláusulas dispersas de una estética y una poética” que, como afirma Stratta, "pueden leerse cifradas en la masa de textos que Borges escribió para revistas y diarios (Sur, La Nación, Crítica, El Hogar, Davar y otros) en las décadas del treinta y el cuarenta, en los ensayos y conferencias que dedicó a narradores [...] y también en las acciones críticas y editoriales emprendidas en colaboración con Bioy Casares” (2004: 49). 
Alberto Giordano afirmó que "la ética de ensayista" que funciona en Borges es "la del lector ingenuo o inocente, la del que sólo escribe, aun cuando responde a las demandas culturales, sobre lo que aumenta su potencia de pensar, imaginar e interrogarse, de experimentar en la escritura su legítima rareza” (2005: 18). El solapado diálogo que Borges mantiene con Stevenson en sus ensayos sobre el realismo pone de manifiesto que la ética borgeana es la del lector que, ingenuo o informado, reconoce en el encanto de lo literario su fuerza principal. El elogio del entusiasmo es el impulso que signa la ensayística del Borges stevensoniano lector del realismo. Una verdadera vindicación del placer de la lectura, que tanto vale para el lector incauto como para el iniciado en los rigores de las tramas y los géneros -cuando no de la crítica literaria-, cuyos saberes, indiscerniblemente unidos como lo están a su disposición infantil a la lectura, propician también de estímulo para su asombro ${ }^{7}$.

El prólogo a La invención... entredice desde el comienzo la ética de lectura hedonista que Borges promueve. Su comentario se abre con una disquisición acerca del tipo de relato que los lectores encuentran interesante y placentero. Anota primero una opinión de Stevenson según la cual los lectores británicos de su época desdeñaban un poco las peripecias ${ }^{8}$, y presenta después, con su arbitrariedad habitual, el examen que hace Ortega:

${ }^{7}$ En "Un chisme sobre la novela” (“A Gossip on Romance”, que aparece por primera vez en noviembre de 1882 en Longman's Magazine 1), dice Stevenson que el hecho de que la literatura consiga conmocionar al lector y asombrar su imaginación "[e]s lo más elevado y lo más difícil que se puede hacer con palabras, eso que, una vez logrado, deleita por igual al colegial y al sabio" (2008: 206).

${ }^{8}$ La cita de Stevenson corresponde a su ensayo "Un chisme sobre la novela", en el que afirma: "Los ingleses de nuestra época tienden, no sé por qué, a subestimar ligeramente las peripecias, y reservan su admiración para el tintineo de las cucharitas de té y los acentos de los curas. Creen que resulta inteligente escribir una novela que no tenga ninguna historia o que, por lo menos, sea muy aburrida.” (2008: 206-7). Daniel Balderston opina que Borges desfigura el sentido de este comentario, al sugerir "aparentemente que Stevenson disculpaba la insistencia en las cucharas de té y la conversación tranquila, cuando en realidad como sabemos, siempre prefirió las 'aventuras al aire libre'” (1985: 24). A mi entender, al contrastar la cita de Stevenson con su referencia en el Prólogo, se observa que la paráfrasis de Borges reproduce el tono irónico del original ("Stevenson, hacia 1882, anotó que los lectores británicos [...] opinaban que era muy hábil redactar una novela sin argumento, o de argumento infinitesimal, atrofiado”, Borges 2005: 7), y deja bastante claro que Stevenson menospreciaba el gusto de esos lectores. La cita equívoca, en realidad, no es tanto la del ensayo de Stevenson -de cuya filiación el Prólogo da explícitas muestras-, como la del de Ortega. Sobre el modo en que Borges deforma las tesis de Ortega, consultar el riguroso análisis de Podlubne (2011: 69-81). 
José Ortega y Gasset -La deshumanización del arte, 1925- trata de razonar el desdén anotado por Stevenson y estatuye en la página 96, que “es muy difícil que hoy quepa inventar una aventura capaz de interesar a nuestra sensibilidad superior”, y en la 97, que esa invención “es prácticamente imposible”. En otras páginas, en casi todas las otras páginas, aboga por la novela "psicológica” y opina que el placer de las aventuras es inexistente o pueril. (Borges, 2005: 7)

Desde esta plataforma que hábilmente construye para montar su argumentación, concluye que el placer que provoca la lectura de las novelas de aventuras es desestimado por el común de los escritores “de 1882, de 1925 y aun -agrega- de 1940”, pero que felizmente existen otros "entre los que [le] place contar -dice- a Adolfo Bioy Casares”, que "creen razonable disentir" (ídem). El “intrínseco rigor” de la novela de peripecias y su explícito carácter de “objeto artificial” resumen, para Borges, los motivos de ese disentimiento, a los que añade una razón de orden "empírico": la primacía que según él tiene el siglo XX en su capacidad de "tejer tramas interesantes” y de “admirable argumento” (ídem).

La rigurosidad en el método de construcción del verosímil asegura para el ensayista el favor y el fervor del lector, como ocurre -afirma- en la novela de aventuras. No obstante el Prólogo parece centrarse en una acérrima defensa de este género literario, la preocupación dominante, aunque disimulada, reside en verdad en cuestiones de técnica literaria centrales a las teorías del realismo. El texto insiste en señalar con precisión los rasgos diferenciales de los relatos de carácter mimético y de los de carácter artificial, a partir de argumentos que contraponen el procedimiento narrativo frente al descriptivo.

La concepción del relato de ficción como objeto eminentemente artificial atestigua su parentesco con ciertas ideas de Stevenson acerca de los personajes ficcionales, a las que Borges se refiere "con frecuencia y con aprobación”, como anota Balderston (1985:71). En el ensayo “Algunos caballeros de ficción”9, Stevenson caracteriza de este modo a los personajes:

Estos muñecos verbales (por así llamarlos otra vez) son cosas de origen dividido: el soplo de vida podría ser una emanación de su hacedor, pero ellos mismos son sólo sartas de palabras y partes de libros; habitan la literatura y pertenecen a ella; la carne y la sangre de que están dotados son la convención, el artificio técnico, el gusto por la técnica, las necesidades mecánicas del arte. (Citado en Balderston, 1985:71)

${ }^{9}$ La primera edición del ensayo “Some Gentlemen in Fiction” es de 1888, en Scribner's Magazine 3, junio: 764-8. 
Borges aprobaría esta definición en lo esencial, aunque estaría en desacuerdo, conjetura Balderston, con el supuesto "origen dividido” según el cual la animación de los personajes les sería infundida por el escritor a la manera de un dios que participa a sus criaturas de su espíritu vital. En efecto, esta idea resulta un resto arcaico en la concepción de Stevenson del realismo literario, con el que parece dar un paso atrás respecto de aquel que adelanta con sus postulaciones acerca de la convencionalidad de la literatura. Algo similar ocurre cuando considera las diferencias entre drama y narración. En su libro Familiar Studies of Men and Books (1882), cuyas observaciones críticas se encuentran en sintonía con su teoría de la novela de aventuras, según afirma Balderston (1985:68), Stevenson incluye un ensayo sobre Víctor Hugo en el que declara:

\begin{abstract}
En el drama la acción se desarrolla principalmente mediante cosas que permanecen al margen del arte; es decir, cosas reales, y no convenciones artísticas de cosas... Ahora todas esas cosas, que permanecen como eran en la vida, y no son transmutadas en una convención artística, son terriblemente porfiadas y difíciles de manejar... Cuando pasamos a la novela de aventuras, vemos que ocurre de otra manera. Aquí nada se reproduce directamente para nuestros sentidos. ... Al haberse perdido gradualmente ese realismo que hemos descrito (en el drama), el arte gana evidentemente en libertad y capacidad. ... Sólo renunciando a esas identidades el arte gana verdadera fuerza.... (Citado en Balderston, 1985:69)
\end{abstract}

De aquí sólo se sostiene -y es lo que Borges recupera- la oposición global entre mímesis y artificio, pero resulta en extremo candorosa su idea de que el drama reproduce la realidad tal cual es, como si el realismo demandara una represión de la imaginación. Si desconfiamos de la aparente ingenuidad de Stevenson al afirmar que el arte mimético presenta las cosas como son en la realidad, sin mediación artística, podemos conjeturar que esta contraposición le permite reforzar su argumento a favor de los procedimientos de la novela de aventuras. Esto lleva a pensar que tanto para Stevenson como para Borges se trata, antes que de una verdadera impugnación del realismo, de una contundente vindicación de la literatura de imaginación. Los dos sostienen una concepción de la literatura según la cual la única narración que merece llamarse tal es la del relato de imaginación, que al menos para Borges, no excluye per se al relato realista. Prueba de ello es su ensayo "Eduardo Gutiérrez, escritor realista”: "No sé -dice Borges en 1937- si el 'verdadero' Guillermo Hoyo fue el hombre de viaraza y de puñalada que describe Gutiérrez; sé que el Guillermo Hoyo de Gutiérrez es verdadero" (1986: 118) ${ }^{10}$.

${ }^{10}$ El hecho que para Borges "salva” a esta novela de prosa trivial es "un hecho que la inmortalidad suele preferir: se parece a la vida” (1986: 119). Un año antes rescataba en $L a$ 
El modo en que Borges-Stevenson formulan el problema del realismo literario deja deliberadamente de lado las dimensiones de la realidad y de la verdad, para ceñirse al propio campo de la verosimilitud y de los artificios creadores de verdades eminentemente literarias. Borges ajusta ciertos tanteos del precursor $-\mathrm{y}$ es de este modo que lo convierte en precursor-, al extender hacia otras manifestaciones del arte el argumento según el cual toda narración supone una realidad convencional y artificial: dirá entonces, corrigiendo el desliz de Stevenson en torno al drama, que "todo arte es convencional"11.

Toda literatura es, para Borges, literatura de imaginación. En la artificialidad de lo literario se funda su tesis sobre la postulación de la realidad, con la que combate aquella concepción del realismo basada en "la policía de las pequeñas distracciones” (Borges, 1996: 400), según la gráfica expresión que emplea en el prólogo a El informe de Brodie. No interesa la "verdad" de los detalles; lo que le importa a la literatura es montar una versión de los hechos, una cautivante, seductora versión. La eficacia del estilo borgeano ha impedido hasta hoy percibir que la literatura de imaginación no se identifica para él únicamente con la modalidad fantástica. Habría que pensar si en verdad la contraposición que formularon las lecturas críticas iniciales no funciona cabalmente sólo en el caso de Stevenson, mientras que en el de Borges se trataría, como mucho, de una estratégica recuperación de las banderas stevensonianas del romance, con el único objeto de reforzar su argumentación, de cimentar su ataque a la modalidad narrativa que amonesta a través del infalible dispositivo retórico de la antítesis, la siempre diáfana y contundente dicotomía.

estatua casera, de Bioy Casares, esa misma -casi la única- virtud: "Entiendo que en 'La vida múltiple de Juan Ruteno’ los capítulos mejores son asimismo los que se parecen más a la realidad” (1999a: 131). El libro de Bioy, anota Borges en la misma reseña, “empieza por una enérgica vindicación de los cuentos fantásticos” (1999a:130). Como previendo los malentendidos que sus propias afirmaciones suscitarían mucho después, aclara que si una vindicación tal es propicia, no lo es por su “índole moral”, sino por la complejidad argumental que supone un buen relato fantástico, como cualquiera de G. K. Chesterton, frente a las resoluciones narrativas "cobardes", que apelan al "todo era un sueño" para escamotear las explicaciones fantásticas. No son posturas morales las que se enfrentan en la dicotomía realista/fantástico, sino colocaciones estratégicas en contextos polémicos. Una toma de posición a favor, no de un género, sino de un lector que no quiere ser burlado en su inteligencia.

${ }^{11}$ En "La poesía gauchesca”, al referirse al Fausto de Estanislao Del Campo, Borges se mofa de quienes "han censurado que un rústico pueda comprender y narrar el argumento de una ópera” porque “olvidan que todo arte es convencional” (1996: 29-30). Entre los que perpetran esos olvidos se contaría, en un juego anacrónico, el nombre de Robert Louis Stevenson, que quiere ver la vida misma en una representación teatral, casi como el rústico de Del Campo. 
Ni su acusación es contra el realismo en tanto modo literario ni su alegato es a favor del anti-realismo en este sentido. Si en verdad le negara al realismo cualquier virtud artística, no escribiría, años más tarde, en el prólogo a El informe de Brodie que, ahora que "conoce el oficio" y cree "haber encontrado [su] voz", ha emprendido la redacción de cuentos que "son realistas" y observan "todas las convenciones del género, no menos convencional que los otros" (Borges, 1996: 399-400). Claro que esos años más tarde hacen la diferencia: en los setenta Borges es un escritor consagrado, su lugar privilegiado en el campo literario está ya fuera de discusión y no constituye una preocupación ni un motivo de disputa como lo era en los cuaren$\mathrm{ta}^{12}$. La confrontación no se entabla entonces con el realismo en tanto escuela literaria, sino frente a un realismo: un tipo de realismo cuyos procedimientos, si son cuestionados, es desde la convicción de que sus resultados no son los que un lector espera de la literatura. Revisemos, en tal sentido, el modo en que se refiere al realismo de Proust, con el que Ortega identifica a la "novela psicológica":

...prefiere que olvidemos su carácter de artificio verbal y hace de toda vana precisión (o de toda lánguida vaguedad) un nuevo toque verosímil. Hay páginas, hay capítulos de Marcel Proust que son inaceptables como invenciones: a los que, sin saberlo, nos resignamos como a lo insípido y ocioso de cada día. La novela de aventuras, en cambio, no se propone como una transcripción de la realidad: es un objeto artificial que no sufre ninguna parte injustificada. El temor de incurrir en la mera variedad sucesiva [...] le impone un riguroso argumento. (Borges, 2005: 8, subrayado mío)

Los procedimientos con los que este realismo opera y los efectos de lectura que los mismos producen son referidos con calificativos que Borges va a repetir hasta el cansancio cada vez que, en sus ensayos de las décadas del treinta y el cuarenta, se refiera al estado de la novela argentina: con adjetivos como "vana", "lánguida", "mera”, “insípida” u "ociosa” la pintará por entero. El método de acumulación de "toques verosímiles” define para Borges un realismo sin invención, que resumirá en la cláusula de la reseña a Las ratas, de 1944, como "mera verosimilitud sin invención” (1999a: 274), y al que ya se había referido en 1937, a propósito de Luis Greve, muerto como "mera acumulación de ocurrencias" (1999a: 150). Si nos detenemos

${ }^{12}$ Desde una nueva posición enunciativa en el campo intelectual, Borges mantiene sin embargo su apuesta por la artificialidad de lo literario - esta vez apelando a las formas convencionales del realismo-, frente a las intenciones moralizantes, didácticas y propagandísticas de cierta literatura realista. Sobre las continuidades y giros que, en su tratamiento del realismo y en función de su relación con el ambiente intelectual de la época, se reconocen en el Borges de El informe de Brodie, respecto del de los años treinta y cuarenta, consultar el trabajo de Annik Louis (2008). 
un momento en su particular elección léxica, tenemos que este proceder que opta por lo simple, lo mero, lo vano y lo elemental, remite a una literatura cuyos efectos son igualmente "insípidos", ininteresantes, sin atractivo. Lo que Borges declara inaceptable en literatura es, antes incluso que la carencia de rigor formal, la carencia de interés, de encanto. Reprueba las páginas en las que la narración se deja ganar por lo "insípido y ocioso", del mismo modo en que Stevenson censura "lo tedioso" en el ensayo "Una nota sobre el realismo""

el artista -prescribe Stevenson- cuenta con un recurso principal y necesario que debe, en cualquier caso y bajo cualquier teoría, emplear. Debe, esto es, suprimir mucho y omitir más. Debe omitir lo que resulta tedioso o irrelevante, y suprimir lo que resulta tedioso y necesario. Pero los datos que, vistos a la luz del esquema principal, están al servicio de varios propósitos, los conservará ineludiblemente y con entusiasmo. Y es la marca de la clase más elevada de arte creativo el que se construya exclusivamente con ellos. (2008: 233, subrayado mío)

Omitir lo tedioso, dice Stevenson, cuando es irrelevante, pero omitirlo también aun cuando es necesario para la trama. Los rigores formales de la construcción están supeditados a una posición ética frente a la literatura según la cual ésta debe garantizar ante todo el placer del lector. Stratta afirma que "[a] la hegemonía de la gran novela, Borges no le opone una teoría del cuento, pero sí una poética de la narración disciplinada y económica” (2004: 53). En realidad, detrás del sistema de oposiciones que Borges postula -brevedad / dilatada extensión, rigor constructivo / informidad, orden / desorden-, lo que está en juego es un modo de entender la literatura al que le interesa menos el rigor formal de la construcción que el insoslayable, irrenunciable don de encantar. La narrativa que Borges elogia, haciendo creer que la identifica exclusivamente con la "novela de aventuras", es aquella que "no sufre ninguna parte injustificada". Pero esta austeridad y concisión de la trama no son, en verdad, lo decisivo para Borges. Lo que en última instancia le otorga a un detalle, una expresión o una mención cualquiera el pleno derecho de figurar en el texto es que dicha incorporación redunde en el encantamiento del lector, aquello capaz de suscitar el hechizo de la lectura. Un dato puede no ser relevante para la trama, puede incluso no ser preciso -este tipo de reservas le resultan absurdas ${ }^{14}$-,

13 “A Note on Realism” se publica en noviembre de 1883 en The Magazine of Art 7.

${ }^{14}$ De ellas se vuelve a burlar en 1960, en el prólogo a El informe de Brodie: "Por increíble que parezca, hay escrupulosos que ejercen la policía de las pequeñas distracciones. Observan, por ejemplo, que Martín Fierro hubiera hablado de una bolsa de huesos, no de un saco de huesos, y reprueban, acaso con injusticia, el pelaje overo rosado de cierto caballo famoso" (1996: 400). 
pero si gusta, está justificado. A este respecto, y en relación con la centralidad que le concede al placer literario, declara en "La poesía gauchesca"15.

Apenas si me atrevo a confesar que aunque los gauchos de más firme ortodoxia menosprecien el pelo overo rosado, el verso

En un overo rosao

sigue -misteriosamente- agradándome. [...] Pasan las circunstancias, pasan los hechos, pasa la erudición de los hombres versados en el pelo de los caballos; lo que no pasa, lo que tal vez será inagotable, es el placer que da la contemplación de la felicidad y de la amistad. Ese placer, quizá no menos raro en las letras que en este mundo corporal de nuestros destinos, es en mi opinión la virtud central del poema. (Borges, 1999b: 29-30; fuera del verso de Del Campo, el subrayado es mío)

Contra el "vano detalle"16, Stevenson prescribe mantener sólo los datos que importan, de modo que la narración se edifique en base a lo que Borges formulará, en "La postulación de la realidad" (1931), como el método de la "invención circunstancial”, basado en "el desenvolvimiento o la serie de esos pormenores lacónicos de larga proyección” (Borges, 1999b: 100-101) ${ }^{17}$. La cuestión se dirime entonces, para ambos, en un enfrentamiento de dos modos narrativos, dos procedimientos de construcción del relato: la consabida disputa entre "showing” y "telling". El resto de las dicotomías que Borges traza se revelan lábiles: la oposición entre argumento conciso y trama de patrón único, por un lado, e "incontrolables e infinitas operacio-

${ }^{15}$ Este ensayo aparece por primera vez en 1931 en Sur 2 (mayo), bajo el título de "El Martín Fierro", y luego es recogido en la edición de 1957 de Discusión, con el título "La poesía gauchesca”.

${ }^{16}$ Tal es la expresión que usa Borges en la reseña "La espada dormida”: "Tales artificios impiden que para juzgar la ficción (en la que priman el rigor y el asombro) se recurra a la mera realidad (en la que priman la rutina y la delación, el imprevisible azar y el vano detalle)" (1999a: 283)

${ }^{17}$ Stratta afirma que, en "La postulación de la realidad”, Borges se basa una traducción libre de los argumentos de Stevenson contra el detalle: “[e]n 'Nota sobre la novela', de 1886, -escribe- Stevenson elogia el espíritu simplificador del siglo clásico francés”, en oposición al de las narrativas del siglo XIX que "rindieron un culto creciente al virtuosismo de la representación minuciosa” (2004: 52). En realidad, el ensayo al que se refiere es "Una nota sobre el realismo” (“A Note on Realism”), de 1883, aunque no es casual la confusión con "Un chisme sobre la novela” (“A Gossip on Romance”), de 1882, en el que Stevenson desarrolla su idea de lectura hedónica. La referencia que da la autora probablemente corresponda a una reedición de 1886 del primero de los ensayos. El fallido de Stratta es significativo, puesto que ese cruce de ensayos avala la hipótesis de que la más contundente herencia de Stevenson radica en su elogio del encanto de la lectura. 
nes” (1999b: 126), por otro, así como el enfrentamiento entre asunto extraordinario versus asunto realista evidencian ser más dignos de una hábil maniobra de retórica opositiva que de una sólida toma de posición por los primeros términos de la antítesis. La discusión de fondo es la que se dirime en torno a los fines de la literatura. Es desde la idea de la literatura como encantamiento que le viene de Stevenson, que Borges se involucra en una discusión central a las teorías del realismo como es la de la polémica alternativa entre narrar o describir, de la que Lukács (1936) se ocupará, como Stevenson, también a propósito de las novelas de Émile Zola ${ }^{18}$.

La preocupación que en última instancia motiva, tanto en Borges como en Stevenson, la reflexión sobre las cuestiones de la invención y la ejecución del relato no es otra que ¿cómo escribir un relato que cautive al lector? Si ambos responden tomando partido en favor de la narración, contra la descripción, es porque la apuesta que los convoca es la de dividir las aguas entre las literaturas que aburren y las que conmueven. Es clara, al respecto, la manera en que Borges formula la exigencia del rigor constructivo en el parágrafo citado más arriba del prólogo a La invención de Morel: el riguroso argumento se impone como la única receta posible que asegura

${ }^{18}$ A pesar de que tanto Lukács como Stevenson coincidan en el interés por la dicotomía narrar/describir, así como en la defensa del método narrativo, hay que destacar la notable diferencia de perspectivas que los separa. A Lukács le interesa la “conexión épica” por el modo en que resulta reveladora de la praxis humana, mientras que para Stevenson el interés de la conexión entre episodios es el de garantizar que la aventura proporcione el entretenimiento del lector. En relación con el modo en que cada uno caracteriza los métodos narrativo y descriptivo, se acercan, sin embargo, en más de un punto. Ambos identifican, por ejemplo, a la técnica narrativa como aquella que propicia la activa participación del lector, por oposición a la descriptiva, que se limita a promover una actitud contemplativa. Dice Stevenson: “... mientras leemos una historia, nos debatimos entre dos estados de ánimo, o aplaudir simplemente el mérito de la representación o consentir en participar activamente en la fantasía, junto con los personajes. Este último es el triunfo de la novela; cuando el lector interpreta conscientemente el papel del héroe, la escena es buena. [...] cuanto más claramente están descritos [los personajes], más se alejan de nosotros, más imperiosamente nos devuelven a nuestro lugar de espectadores.” (2008: 211). Lukács, por su parte, considera la oposición observación/participación no sólo como resultado de la utilización de métodos de representación diferentes, sino sobre todo en relación con "la posición de principio asumida por los escritores hacia la vida” (1977: 39). En este sentido, afirma: "En Scott, Balzac o Tolstoi conocemos acontecimientos que son importantes en sí mismos, por los avatares de los personajes que participan en ellos y por lo que significa, en la vida de la sociedad, el variado desarrollo de la vida de esos personajes. [...] Como lectores, podemos vivirlos.” (ídem). Y continúa: "En Flaubert y en Zola los personajes también son espectadores, más o menos interesados de los acontecimientos y por esa razón se transforman, a los ojos del lector, en un cuadro o mejor dicho, en una serie de cuadros. Como lectores, podemos observarlos” (ídem). 
no caer en la insípida, la ociosa, la "mera variedad sucesiva”. Más explícito en cuanto a lo que un escritor debe aspirar y lo que debe, en consecuencia evitar es este momento del ensayo de Stevenson:

el artista puede incurrir fácilmente en el error de los naturalistas franceses, y considerar que cualquier dato se presta a ser admitido si da pie al trabajo artesanal brillante, o también en el error del pintor de paisajes moderno, que tiende a pensar que la dificultad superada y la ciencia bien exhibida pueden sustituir a lo que es, al fin y al cabo, la excusa y el aliento del arte: el encanto. (2008: 234, subrayado mío)

Lo que Stevenson le achaca a los naturalistas franceses es el uso de la literatura como laboratorio científico:

Una cosa es observar y diseccionar, con la lógica más penetrante, las complicaciones de la vida y del espíritu humano ${ }^{19}$, y otra muy distinta darles cuerpo y sangre en la historia de Ayax o Hamlet. Lo primero es literatura, pero lo segundo es también otra cosa, porque, además, es arte. (2008: 206)

El modo de entender la literatura del naturalismo francés supone, para Stevenson, traicionar los legítimos móviles del arte literario, cuya máxima consumación se logra cuando la lectura resulta un proceso "absorbente y voluptuoso" (Stevenson, 2008: 201). El riesgo de aquel que "con meticulosidad científica, transmite constantemente material que no merece la pena saberse” (Stevenson, 2008: 235) es el de abrumar al lector y desalentarlo, cuando lo que la narración debería despertar en él es justamente su entusiasmo. Motivar la complicidad del lector es indispensable para que el efecto de verosímil ocurra, para despertar "ese sueño voluntario que se llama la creación artística", como dice Borges en "El escritor argentino y la tradición" (1999b: 222). En la reseña que dedica a Las ratas, enfatiza esta virtud de la novela de Bianco:

Es de los pocos libros argentinos que recuerdan que hay un lector: un hombre silencioso cuya atención conviene retener, cuyas previsiones hay que frustrar, delicadamente, cuyas reacciones hay que gobernar y que presentir, cuya amistad es necesaria, cuya complicidad es preciosa. [...] ¿Cuántos escritores de nuestro

${ }^{19}$ En estos términos se refiere Zola a su proyecto literario en La novela experimental [1880], que define en función de la aplicación del método experimental a la novela y el drama: "Yo trataré de probar, a mi vez, que si el método experimental conduce al conocimiento de la vida física, debe conducir también al conocimiento de la vida del sentimiento y de la inteligencia” (s/f: 6-7). 
tiempo sospechan esa necesidad? ¿Cuántos, en vez de interesar al lector, no se proponen abrumarlo e intimidarlo? (Borges, 1999a: 272)

Esos "escritores de nuestro tiempo", a algunos de los cuales no se priva de mencionar después -"los Payró y los Gálvez"20-, comenten el imperdonable error de no poner el acento en el interés del lector y son los que abaten nuestra literatura con el "melancólico influjo" que les viene de la literatura francesa ${ }^{21}$. Este diagnóstico es el que Borges lee en la advertencia de Stevenson a los realistas franceses: "El peligro inmediato del realista es sacrificar la belleza y el significado del conjunto por la destreza puntual, o, en la necia búsqueda de la totalidad, inmolar a sus lectores bajo los datos” (Stevenson, 2008: 235). Cuando con similares argumentos Borges critica la compulsión informativa de la novela argentina, su incapacidad para omitir lo ininteresante ${ }^{22}$, lo que censura no es la materia de la que se vale la literatura realista ni el pacto de lectura que ésta propone. "Esta cuestión del realismo -explica Stevenson-, entiéndase bien, no concierne en absoluto a la verdad fundamental de una obra de arte sino sólo al método técnico" (2008: 231). Apoyándose en la habilidad con la que Stevenson defiende el encanto de la literatura como su fin principal contra la concepción zoliana, que subordina la literatura a una finalidad trascendente ${ }^{23}$-, Borges hará lo propio en el ámbito nacional y censurará los fines morales ${ }^{24}$ a

${ }^{20}$ Y a otros, como Güiraldes y Lynch, alude cuando ataca al género “considerado patriótico" (1999a: 273).

${ }^{21}$ Por oposición, compara la novela de Bianco con La invención de Morel, ya que en ambas "prima el influjo de las literaturas de idioma inglés: un rigor más severo en la construcción, una prosa menos decorativa pero más pudorosa y más límpida” (1999a: 273). Lo central en la lectura de Borges de estos relatos es el modo en que consiguen captar el interés del lector y su complicidad.

${ }^{22}$ Contra los "[t]res géneros [que] agotan la novela argentina contemporánea”, dispara en su reseña a Las ratas: "Los héroes del primero no ignoran que a la una se almuerza, que a las cinco y media se toma el té, que a las nueve se come, que el adulterio puede ser vespertino [...]; el buen manejo de esa erudición les permite durar cuatrocientas páginas.” Ese género, mal llamado -dice Borges- "psicológico", no difiere mucho del "considerado patriótico", cuyos "redactores son incapaces de omitir el pelo de los caballos, las piezas de un apero, la sastrería minuciosa de un poncho y los primores arquitectónicos de un corral”. Contra el tercer género se pronuncia, asimismo, por "no est[ar] destinado a la lectura, sino a satisfacer, tenebrosamente, las vanidades del autor...” (1999a: 273).

${ }^{23}$ En este sentido, Zola estatuye que "[e]l novelista va en busca de la verdad” (s/f: 15$)$

${ }^{24}$ No es, sin embargo, el contenido moral de una obra lo que se censura, sino la primacía del interés moral por sobre el interés novelesco. Para Stevenson, ambos intereses se desarrollan juntos en el cuerpo de la novela y son inherentes a ella. No puede haber, por consiguiente, un interés moral que sea anterior o superior a la novela misma (Stevenson, 2008: 208). Pero si el contenido moral estuviera ausente de la obra, “[l]a aventura, en los términos más 
los que la novela realista suscribe. Es una mera “superstición”, dirá en la reseña a la novela de Peyrou, juzgar "que un libro que debate un problema es, de antemano, superior a otro libro que únicamente quiere encantar" (Borges, 1999a: 282). Y continúa:

Sin embargo, las irresponsables 1001 Noches han sobrevivido a infinitos poemas alegóricos [...]. La espada dormida es, ante todo, un libro agradable. ¿'Necesitaré agregar que ese epíteto no encierra el menor matiz de condescendencia y que un libro que propone (y que logra) la felicidad del lector es, en cualquier época de la historia, en cualquier país del planeta, algo agradecible e impar? (1999a: 282-283)

A la luz de estas conclusiones, podríamos con justicia dar vuelta la fórmula que proponía el pionero ensayo de Beatriz Sarlo sobre el "formalismo criollo", cuando afirmaba que a Borges "le importa más el cómo que el porqué" (1982: 4) ${ }^{25}$. El reverso exacto de esta sentencia se revela en función del diálogo con el precursor: el rigor constructivo no es el precepto principal sino más bien el resultado y la consecuencia de una potencia anterior: la de encantar, seducir; no aburrir, no abrumar. Se hace cada vez más evidente que los preceptos formalistas que Borges prescribe no son lo esencial para él, y están supeditados a una ética menos coyuntural y variable. El principal impulso que los ensayos de Borges toman de los de Stevenson, el eje desde el que el ensayista tracciona el movimiento de su enunciación es lo que defino como una ética del lector hedonista. Un lector cuya relación con la literatura está, por sobre cualquier otro interés, motivada por el de "deleitarnos con el libro, embelesarnos y olvidarnos de nosotros mismos” (Stevenson, 2008: 201).

La insistencia con la que ambos ensayistas se refieren a la necesidad de "cautivar", “conmover”, "embelesar”, debe su explicación a que dicho efecto de encantamiento funciona como garantía del realismo por el que abogan. La lógica de los ensayos de Borges y Stevenson propone una singular idea de realismo entendida como aquel efecto de realidad que la "suspensión de la incredulidad" -en virtud de la que tanto insiste Borges en sus alusiones a Coleridge- suscita en el que lee. Este realismo es, en última instancia, un efecto de lectura. Si se lee el Prólogo a $L a$ invención... junto con "El arte narrativo y la magia” y "La postulación de la reali-

básicos, proporciona el entretenimiento, y se la considera suficiente” (2008: 209). Similares argumentos empleará Borges en su intervención en el debate de Sur 126, "Moral y Literatura”, en la que declara que vedar el contenido moral significaría "empobrecer la literatura”, pero el juicio moral del autor "importa poco" (1945: 71).

${ }^{25}$ Desde un interés diferente al nuestro, Giordano (2005) ya había desmontado la lectura de Sarlo y concluía: "No creemos que se pueda identificar a Borges con el formalismo, que en el centro del sistema borgiano domine el procedimiento” (31). 
dad”, queda claro que la retórica ensayística anuda la cuestión de la lectura hedónica con los problemas del realismo. La trilogía compone, en su conjunto, un análisis de los procedimientos narrativos a través de los cuales es posible hechizar al lector de forma tal que éste, imbuido en el placer de la lectura, complete el efecto de realidad que propone el texto. Este procedimiento es el definido por Borges en "La postulación..." como el "método clásico" -por oposición al "romántico”-, aquel que encomienda una continua fe en el lenguaje, que propone antes que imponer, que es de orden sugestivo y mediato:

El autor nos propone un juego de símbolos, organizados rigurosamente sin duda, pero cuya animación eventual queda a cargo nuestro. No es realmente expresivo: se limita a registrar una realidad, no a representarla. Los ricos hechos a cuya póstuma alusión nos convida, importaron cargadas experiencias, percepciones, reacciones; éstas pueden inferirse de su relato, pero no están en él. Dicho con mejor precisión: no escribe los primeros contactos con la realidad, sino su elaboración final en conceptos. (Borges, 1999b: 94)

La verosimilitud es, según este método, el vehículo para conquistar la fe del lector, que es la que le concede vitalidad a las "vidas de papel" que presenta un relato. La espontánea suspensión de la incredulidad ${ }^{26}$ es el impulso que anima la vida ficcional del relato. La investigación que desarrolla Stevenson en "Un chisme sobre la novela” sobre la realidad ficticia se ocupa, según señala Balderston, del funcionamiento de la imaginación del lector. Tanto para Stevenson como para Borges,

la mejor manera de hacer del lector un activo colaborador en el proceso de la creación consiste en combinar dos impulsos contrarios: dirigirse hacia abstracciones generalizadas, por un lado, y hacia 'detalles sorprendentes', por el otro. [...] [Se busca] excitar la imaginación del lector con detalles fascinantes. (Balderston, 1985: 26)

El problema de la verosimilitud involucra para ambos una cuestión de abstracción y de selección. La prescripción de Stevenson, primero, y de Borges, después, de omitir el detalle en la narración responde al concepto de verosímil que sustenta su ética literaria. El interés de ambos por "la impersonalidad y la abstracción del clasicismo", concluye Balderston, tiene que ver con que este método hace posible que el relato "permanezca de algún modo abierto y ambiguo, y resulte sugestivo por su mismo carácter incompleto" (1985: 29). En este sentido, la imputación que realizan a la novela realista reside precisamente en que, al abundar en detalles y

${ }^{26}$ The “willing suspension of disbelief” es la fórmula con la que Samuel Taylor Coleridge define a la fe poética en su Biographia Literaria (1817). 
particularidades, coarta la imaginación del lector. En su pretensión de exhaustividad, el detalle realista atenta contra el realismo por el que abogan Borges/Stevenson, el de aquella realidad sugerida que el lector completa en su imaginación. La técnica que Borges formula como "invención circunstancial” y que Stevenson recomienda emplear en "Un chisme sobre la novela", radica en el empleo de ciertos detalles que "persuaden" al lector para que "abandone su reserva" y colabore en el proceso de creación literaria imaginando más de lo que se le refiere. Si para Stevenson la narración se mueve a partir de esos detalles que llevan al lector más allá del texto, los que, además, deben apuntar todos hacia un fin común, Borges en el "El arte narrativo y la magia" dirá que los hechos de una narración se hallan concatenados entre sí por arte de la "causalidad mágica", rectora de un orden en el que "profetizan los pormenores". Por un arte narrativo que postula realidad con pormenores proféticos, contra un realismo que no encanta, cuyo método de imponer al lector información vana no sólo no conmueve sino que además abruma.

El realismo de Borges/Stevenson es ante todo una cuestión de fe literaria. El efecto de realidad que procuran nace en el instante mismo en que el lector es seducido de tal modo que quiere volverse cómplice del relato, en el instante mismo en que un detalle cualquiera aviva el hechizo por el que durante unas horas su mente sólo se ocupará de co-crear el mundo que la lectura le sugiere apenas. Realista es cualquier narración que un lector cree posible. No otro sentido podemos otorgarle a la fórmula "fantásticos pero no increíbles", con la que Borges define los cuentos de Bioy en la reseña "Luis Greve, muerto". No por casualidad es idéntica a la que utiliza Stevenson para referirse a los de Verne: "Estos cuentos suyos no son verdaderos, pero no caen del todo bajo el rótulo de imposibles” (en un artículo de 1876 publicado en The Academy, citado en Balderston, 1985: 33).

Balderston afirma que es "probable que la ilusión de verosimilitud surgiera para Stevenson de una narrativa evidentemente no realista -unida como lo está al ensueño, la fantasía y la imaginación- que de una narrativa que se ocupe de la realidad cotidiana" (1985: 23). El matiz que hace falta percibir entre esta propuesta y la de Borges es que en su caso, según expuse, no se sostiene la mentada oposición entre novela de aventuras versus novela de personajes, o entre realismo y antirrealismo sino que tal vez sea la que enfrenta el modo narrativo frente al descriptivo la única antítesis que verdaderamente estructura su argumentación. Que el método narrativo defendido por Borges provenga de la teoría del romance inglés no necesariamente implica que el alcance de este método y de esta concepción de la literatura se detenga en los confines de la novela de aventuras. Si en 1940 la narración fantástica y de aventuras funciona como el paradigma de relato artificial y deliberado, a medida que lo solicitan y promueven las variables coyunturas de los años subsiguientes, 
Borges extiende el atributo de la artificialidad a otros géneros literarios: en 1945, al policial $^{27}$; en los cincuenta, y a propósito de su disputa con el peronismo, a la gauchesca ${ }^{28}$; y en los setenta, cuando ya no importan las viejas rencillas, termina por concedérselo al cuento realista ${ }^{29}$, y cierra con esta última línea el trazado total de una ética literaria.

\section{BIBLIOGRAFÍA}

ALONSO, Amado.

1935 “Borges, narrador”, Sur 14, año 5, noviembre de 1935, pp. 105-115. ARIAS, Martín y Martín Hadis.

2000 Borges profesor. Buenos Aires: Emecé.

BALDERSTON, Daniel.

1985 El precursor velado: R. L. Stevenson en la obra de Borges. Trad. de Eduardo Paz Leston. Buenos Aires: Sudamericana. [Original inglés 1981]

BORGES, Jorge Luis.

1945 Intervención en “Moral y Literatura”, Sur 126, agosto de 1945, pág. 71.

1986 Textos cautivos. Ensayos y reseñas en “El Hogar” (1936-1939). Buenos Aires: Tusquets Editores.

1996 Obras Completas. Buenos Aires: Emecé.

1999a Borges en Sur. 1931-1980. Buenos Aires: Emecé.

1999b Discusión. Buenos Aires: Emecé. [1 $1^{\mathrm{a}}$ ed., Buenos Aires: Manuel Gleizer, 1932; 2a ed., Buenos Aires: Emecé, 1957].

2005 "Prólogo" a Bioy Casares, Adolfo. La invención de Morel. Buenos Aires: Emecé. Edición especial para La Nación. [1 ${ }^{a}$ ed., Buenos Aires: Losada, 1940].

${ }^{27}$ En la reseña "La espada dormida” asevera que al género policial “[p]uede perjudicarlo todo exceso de verosimilitud, de realismo; trátase de un género artificial” (Borges 1999a: 283).

${ }^{28}$ En "El escritor argentino y la tradición” (1957), concluye: “Todo esto puede resumirse así: la poesía gauchesca, que ha producido -me apresuro a repetirlo- obras admirables, es un género literario tan artificial como cualquier otro.” (Borges, 1999b: 209)

${ }^{29}$ En el ya citado Prólogo a El informe de Brodie afirma: "mis cuentos son realistas, para usar la nomenclatura hoy en boga. Observan, creo, todas las convenciones del género, no menos convencional que los otros” (Borges, 1996: 399) 
DABOVE, Juan Pablo.

2008 “Jorge Luis Borges: Políticas de la literatura”, en Juan Pablo Dabove (ed.). Jorge Luis Borges: Políticas de la literatura. Pittsburgh: Ed. del Instituto Internacional de Literatura Iberoamericana de la Universidad de Pittsburgh, pp. 9-28.

GIORDANO, Alberto y Sergio Cueto.

1988 Borges y Bioy Casares ensayistas. Rosario: Ediciones Paradoxa. GIORDANO, Alberto.

1991 Modos del ensayo. Jorge Luis Borges-Oscar Masotta. Rosario: Beatriz Viterbo.

2005 Modos del ensayo. De Borges a Piglia. Rosario: Beatriz Viterbo. GRAMUGLIO, María Teresa.

1989 “Borges, Bioy y Sur. Diálogos y duelos”, en Punto de vista 34, julio-septiembre de 1989, pp. 11-16.

IBARRA, Néstor.

1930 “Jorge Luis Borges, poeta”, en Síntesis, n 34, Buenos Aires, marzo de 1930, p.31.

LOUIS, Annick.

2008 "El testamento. Formas del realismo en El informe de Brodie", en Juan Pablo Dabove (ed.). Jorge Luis Borges: Políticas de la literatura. Pittsburgh: Ed. del Instituto Internacional de Literatura IbeLUKÁCS, György. roamericana de la Universidad de Pittsburgh, pp. 331-354.

1977 “Narrar o Describir? Contribución a la discusión sobre el naturalismo y el formalismo”, en Carlos Altamirano y Beatriz Sarlo (eds.). Literatura y sociedad.

MOLLOY, Sylvia.

1979 Las letras de Borges. Buenos Aires: Sudamericana.

PASTORMERLO, Sergio.

2007 Borges crítico. Buenos Aires: Fondo de Cultura Económica. PEZZONI, Enrique.

1952 “Aproximación al último libro de Borges”, Sur 217-218, noviembre-diciembre de 1952, pp. 101-123. Recogido en Pezzoni, Enrique (1986): El texto y sus voces. Buenos Aires: Sudamericana, pp. 3159.

PODLBUNE, Judith.

2011 Escritores de Sur. Los inicios literarios de José Bianco y Silvina Ocampo. Rosario: Beatriz Viterbo.

SARLO, Beatriz.

1982 "Borges en Sur: un episodio del formalismo criollo", Punto de vista 16, noviembre de 1982, pp. 3-6. 
STEVENSON, Robert Louis.

2008 “Un chisme sobre la novela” [1882] y "Una nota sobre el realismo" [1883], en Alberto Manguel (ed.); Ismael Attrache (trad.). Memoria para el olvido. Los ensayos de Robert Louis Stevenson. México: Siruela, pp. 201-215, 229-235.

STRATTA, Isabel.

2004 “Documentos para una poética del relato”, en Sylvia Saítta (dir.), El oficio se afirma. Noé Jitrik (dir.), Historia crítica de la literatura WAISMAN, Sergio. argentina, vol. 9. Buenos Aires: Emecé, pp. 39-63.

2005 Borges y la traducción. Buenos Aires: Adriana Hidalgo. ZOLA, Émile.

(s/f) La novela experimental. Madrid: La España Moderna (Colección de Libros Escogidos). [1880]. 